\title{
Analyzing the Costs and Benefits of Installing Unmanned Parcel Lockers: Focusing on Residential Complexes in Korea
}

Author(s): Hoang Thai Pham, Hyangsook Lee

Source: Journal of International Logistics and Trade 2019; 17(2):43-54

Published by: Jungseok Research Institute of International Logistics and Trade, Inha University

DOI: https://doi.org/10.24006/jilt.2019.17.2.043

The Journal of International Logistics and Trade is an official journal published by Jungseok Research Institute of International Logistics and Trade, Inha University, Korea. JILT welcomes manuscripts that advance the practice and science of logistics, trade, and other related fields.

Frequency: Quarterly (March, June, September, December)

Stable URL: https://www.ejilt.org

The Jungseok Research Institute of International Logistics and Trade is a specialized academic research institute representing Inha University and the Inha Foundation in Korea. The institute aims to become a representative institute in Northeast Asia in the research of logistics and trade.

Stable URL: https://jrieng.inha.ac.kr

(C) Copyright. Jungseok Research Institute of International Logistics and Trade.

This is an Open-Access article distributed under the terms of the Creative Commons Attribution NonCommercial License (http://creativecommons.org/licenses/by-nc/4.0/) which permits unrestricted noncommercial use, distribution, and reproduction in any medium, provided the original work is properly cited 


\title{
Journal of
}

\section{International Logistics and Trade}

\section{Analyzing the Costs and Benefits of Installing Unmanned Parcel Lockers: Focusing on Residential Complexes in Korea}

\author{
Hoang Thai Pham, Hyangsook Lee* \\ Graduate School of Logistics, Incheon National University, Korea
}

\author{
ARTICLE INFO \\ Article history: \\ Received 02 May 2019 \\ Accepted 30 June 2019 \\ Keywords: \\ Unmanned parcel locker \\ Cost-benefit analysis \\ E-commerce \\ Delivery services \\ Public health
}

Revision received 07 June 2019

\begin{abstract}
A boom in e-commerce in Korea has sparked off high daily-volume demand for smallsized home delivery services, which poses a great challenge to distribution networks, especially in urban areas where traffic congestion, accessibility, and pollution are serious problems. In addition, security issues for people who live in small townhouses and detached houses without security systems and guards have received increasing attention from the government and society. Thus, the introduction of a new alternative for home delivery services, unmanned parcel lockers, is urgent for residents living in these areas. This paper examines and compares potential socio-economic impacts in terms of costs and benefits when such lockers are installed at selected locations in residential areas. The results show that this policy is worthy of adoption, with several undeniable benefits to local communities. In addition, sensitivity analyses estimate the economic performance of this project at different social discount rates, and they check the sensitivity of economic performance based on variations in the variables. The value of travel time savings was identified as a critical and dominating factor directly affecting economic performance.
\end{abstract}

(C) 2019 Jungseok Research Institute of International Logistics and Trade, All rights reserved.

\section{Introduction}

In recent years, Korean e-commerce has experienced rapid revolution as the seventh largest e-commerce in the world and the third largest in Asia, owing to the fastest national broadband internet network in the world and the spread of IT devices, such as computers, laptops, smartphones, and tablets (Yoon, 2017). The Korean domestic e-commerce purchases reached US $\$ 55.9$ billion in 2016, accounting for $17.9 \%$ of the total domestic retail industry (U.S. International Trade Administration, 2017). As a result, this growth has sparked off high daily-volume demand for small-sized home delivery services and poses a great challenge to distribution networks, especially in urban areas where traffic congestion, accessibility, and pollution are serious problems. Besides, a survey of the Korean Ministry of Gender Equality and Family (2016) noted significant trepidation in the elderly and women who are alone when they receive parcels at home from strangers. In addition, the number of conflicts between clients and delivery service companies has increased due to frequently lost or damaged parcels.

In Korea, luxury condominiums and large apartment buildings, offices, or townhouse complexes are equipped with modern security systems and are protected by security guards, who can receive and keep parcels on behalf of absent residents. But small townhouses and detached houses are not equipped with security systems, nor do they have security guards. This creates the threat of crime, and reduces the efficiency and quality of delivery services, especially when customers are absent from home. According to Yoon (2012), it is estimated that the number of small townhouses and

\footnotetext{
* Corresponding author: Graduate School of Logistics, Incheon National University,119 Academy-ro, Yeonsu-gu, Incheon, 22012, Republic of Korea; Email: hslee14@inu.ac.kr
} 
detached houses accounts for approximately $20 \%$ of total urban homes. Thus, the introduction of alternatives for home delivery services is urgent for residents who live in these residential areas.

Therefore, in order to properly solve the above-mentioned problems, the distribution of unmanned parcel lockers, promoted by the Korean government, has been suggested as one effective alternative to traditional delivery services. A Ministry of Land, Infrastructure and Transport regulation requires residential complexes of 500 or more households to install those lockers. At the same time, the Ministry of Security and Public Administration published guidance for installing them and shared several pilot projects. It hopes this new alternative can support effective operations by delivery providers, rationalize costs, and achieve other benefits for the environment, public health, and security across small geographic areas. However, the guidelines are not clear, and the number of exemplary cases is scant (Asia Today, 2014). This confuses local authorities and impedes wide diffusion of unmanned parcel lockers. This paper examines the potential socio-economic impacts when lockers are installed at selected locations in terms of costs and benefits. The results are intended to help authorities recommend whether this policy is worthy of adoption.

\section{Literature review}

\subsection{Cost-benefit analysis}

Transportation policy and planning decisions have a complicated and vital virtual relationship with every aspect of life. Therefore, for a change in these decisions, decision makers often have to carefully consider the trade-offs between conflicting goals and problems. Costs involve monetary costs and non-market costs; some things cannot be traded in the real market, like clean air and crash risks (Litman, 2013). Several other costs are considered indirect costs, which have a long story when connecting to the ultimate outcome (Berger and Associates, 1998). Thus, it is undeniable that, although there may be difficulties in fully measuring indirect or non-market costs, they contribute significant impacts, and hence, should not be ignored in evaluating a project. In this case, a cost-benefit analysis is highly recommended to illustrate expected monetary benefits and costs that projects would produce (Litman, 2009a).

The United States is well-known as the first country that has applied the cost-benefit analysis (CBA) to evaluate waterrelated projects since the 1930s (Hanley and Spash, 1993). CBA has been considered a useful tool that can be applied in appraising policies and projects to evaluate potential socio-economic impacts in terms of costs and benefits, especially in public funding of transport projects (U.S. Department of Transportation, 2007). In the U.S., President Clinton and President Obama issued Executive Order 12866 and Executive Order 13563, respectively, to establish the framework that exercised ascendancy over American agencies when they regulate policies based on a framework of principles released by the federal courts - a new policy is approved only if its benefits are worth more than its costs (Sunstein, 2005). The Commercial Vehicle Information Systems and Networks (CVISN) project in the mid-1990s used CBA to assess improvement in the safety and efficiency of commercial vehicles in the U.S. (Brand et al., 2002). In 1999, the California Department of Transportation (Caltrans) researched a new toll collection system and applied CBA to test a pilot project (Li et al., 1999). After that, in 2002, the Elevated Transportation Company applied CBA in a new monorail project named Green Line to reduce congestion in and near downtown Seattle (DJM Consulting and ECO Northwest, 2002).

Besides, most of the European Union (EU) and other developed countries also share the same status when considering $\mathrm{CBA}$ as a tradition whenever appraisals consider non-market factors, especially environmental effects (Bristow and Nellthorp, 2000). CBA was applied first in the United Kingdom with the M1 motorway project, and later, for the London Underground's Victoria Line (Coombs et al., 2005). After that, in 1998, the Department of Transport proposed the New Approach to Appraisal for national road projects, which then spread to every mode of transport to become a keystone in transport appraisals. In 1999, the Finnish government upgraded a new telematics system that combined real-time information on traffic systems and passengers in Helsinki (Lehtonen and Kulmala, 2002). In addition, a European Network for Education and Training project in 1999 suggested a combined framework between CBA and multi-criteria analysis (MCA) to evaluate economic performance and environmental impacts (Tsamboulas et al., 1999). In 1994, Transport Canada issued its guidebook to promote the use of CBA in transport projects in Canada (Transport Canada, 1994). In Asia, Japan applied CBA to assess the effect of enacting the Studded Tire Regulation Law of 1990, which voted for a new environment-friendly low-PM2.5 tire for cars (Asano et al., 2002).

\subsection{Costs}

The economist's notion of costs is things called "problems" by most people. Costs can involve money, time, resources, or even the trade-off in opportunities or uses of resources to achieve a benefit. There is a rich stream of studies on cost. Keeler et al. (1975) started this stream focusing on transportation by investigating urban transport costs of automobiles, buses, and rail in San Francisco in term of congestion, public services and facilities, environmental pollution (noise and air), safety, parking, etc. Hanson (1992) estimated the external cost of in-city road transportation and introduced costing methods. MacKenzie et al. (1992) reviewed U.S. motor vehicle cost categories, including tolls, parking, air pollution, fuel costs, congestion, traffic accidents, noise, and land loss. In the EU, Kågeson (1993) calculated air and noise pollution, 
safety, and infrastructure costs. After that, various studies were conducted to find out the marginal value in other regions with abundant targets, or introduced improved costing methods.

\subsection{Benefits}

Benefits and costs share a mirror-image effect, and thus, benefits can be defined as cost reduction. The Transportation Economics Board (TRB) suggested several common benefits that we can get from transport projects, including travel time savings, vehicle operating cost savings, safety and health benefits, air emissions reduction, and parking cost savings.

Travel time savings. In recent years, when assessing transport projects, saving time has increasingly received academic attention. Value of Travel Time Savings (VTTS) refers to the benefits of saving time by traveling faster. VTTS is considered a fundamental parameter of project assessment because it represents a large proportion of user benefits (Hensher, 2001; Mackie et al., 2001). There have been considerable discussions to determine which methods can be used to figure out VTTS. From academic papers published up to now, they can be put into three classes: the factor cost, modeling studies, and the meta-analysis. McKinsey and Company (1986) and the National Endowment for the Arts (NEA) (1991) suggested a factor-cost method using data on fuel costs and wage rates to carry out a project in the Netherlands. With this method, the estimated values showed higher reliability due to the actual data; however, in reality, it was difficult to obtain good data, because companies often refused to provide exact data to protect their competitive advantage. Although Widlert and Bradley (1992) suggested a logit model to estimate time value in the early 1990s, until the 2000s, modeling studies have been widely conducted instead of the factor-cost method to clear up the willingness-to-pay aspect. Based on the data used, modeling studies can be divided into revealed preference (RP) studies and stated preference (SP) studies. While RP studies generally depend on actual behaviors of responders (such as travelers, carriers, or shippers), SP studies obtain a database on their preferences. The answers of an SP questionnaire are considered better for the hypothetical purposes of researchers. Finally, the meta-analysis method was initially introduced in 1904, but until 1981, the term "meta-analysis" was named by Glass (1981). Since 1994, this method has been applied extensively in transport projects, especially in studies of VTTS.

Vehicle operating cost savings. According to Allen and Hamilton Inc. (1999), vehicle operating costs (VOC) refers to costs that vary with vehicle usage, including fuel, tires, maintenance, repairs, and mileage-dependent depreciation. VOC reduces in proportion to shorter traveled distances. Following the various previous studies, we analyzed vehicle fuel consumption simultaneously with later emissions-saving issues. Based on data from Caltrans (1974), there is a huge amount of research and many transport projects regarding this topic, especially focusing on VOC of trucks. Zaniewski et al. (1982) analyzed consumption rates and costs derived, and suggested the Highway Economic Requirements System (HERS) models to calculate VOC on general trucks. In a report for the U.S. Department of Transportation, Jack Faucett Associates (1991) focused on analyzing trucking costs per mile by listing and summarizing several previous studies. Berwick and Dooley (1997) presented a spreadsheet simulation model with cost assumptions, collected from truck cost studies, and consultations from trucking experts. According to another report series from Trimac Logistics, Ltd. (2001) in Canada, a MicroBENCOST model was applied to figure out VOC of trucking using information from various sources, including interviews with experts, a review of published studies, and quotes from suppliers of vehicle operation equipment. Besides applying a model to calculate VOC under different driving conditions, Barns and Langworthy (2004) also suggested a way to estimate changes in operating costs in the future. In the most recent research of the American Transportation Research Institute about the operational costs of trucking, Ford and Dan (2015) provided a relatively detailed average cost per mile for trucks from 2008-2014 based on the survey data.

Environmental cost savings. Air pollution can damage human health and leads to climate change. Abundant studies have proven that air pollution contributes to human health problems, including cancers, and cardiovascular and respiratory diseases (HEI, 2010). Increasing amounts of greenhouse gases lead to radiative forcing, making the Earth warmer and causing climate change (Litman, 2009b). Global warming is widely accepted as a significant cost in present and future risks. The United Nations Environmental Program's 2007 Global Environment Outlook called for action to reduce the costs and risks from air pollution (UNEP, 2007).

Fuel combustion makes energy and releases emissions. Therefore, the calculation of emissions is always attached to fuel consumption. Fuel and emissions savings are amounts of fuel and emissions cut down thanks to traveled-distance reduction. Fuel emission-savings calculation models can be divided into macroscopic models and microscopic models. By using average aggregate network parameters to determine network-wide emissions, researchers have introduced a variety of macroscopic models applied to studies and projects. Similar to the macroscopic models used to estimate fuel consumption and vehicle emissions, the microscopic models focus on more detailed calculations. Demir et al. (2014) stated that COPERT software (macroscopic models) and CMEM (microscopic models) are two of the most commonly used. COPERT, sponsored by the European Economic Area, uses a number of regression functions to estimate fuel consumption, as well as the emissions of most major air pollutants from a wide range of vehicles by engine type and vehicle type (Kouridis et al., 2010). CMEM, introduced in Barth et al. (2005), Scora and Barth (2006), and Barth and Boriboonsomsin (2008), is based on collecting data from a test of 343 light-duty vehicles.

Public health benefits. Public health refers to the community's health condition and well-being. Transportation, although in a non-health-related sector, also affects public health positively or negatively, and directly or indirectly. In 
terms of direct impacts, it can improve public health with the use of active transport modes like walking and cycling. In contrast, traffic accident casualties and exposure to poor-quality air can reduce public health. Beyond these, the effects of air pollutants can also be divided into short-term and long-term, which is more serious because of damages to the respiratory system. Indirect effects are often linked to social interactions and accessibility to medical or other services (Waheed et al., 2018). While most assessments of direct impacts on health, such as air quality or crash risks, are quantifiable, the assessment of indirect effects is based typically on qualitative data (Laporte and Dubreuil, 2014). Therefore, consideration of these indirect impacts is often ignored when evaluating projects or policies. That is the reason why Health Impact Assessment (HIA) is highly recommended by the World Health Organization (WHO, 1948, 1999) and research cycles (Mindell et al., 2008; Waheed et al., 2018) to fill this assessment void.

HIA is an evidence-based, multi-disciplinary evaluation approach that examines the expected impacts, both positive and negative, and their distribution within a community (WHO, 1999). Ross et al. (2014) stated that the main advantages of HIAs are the chances for decision-makers to minimize bad health consequences, to optimize health benefits, and to reduce health inequalities associated with projects. Thus, the HIA has become a more popular method in Europe, the U.S., Canada, and the Australian sub-continent (U.S. National Research Council, 2011). It is common for almost all HIAs to use qualitative data for their assessments, although it is difficult to analyze the scale and magnitude of the potential effects if the data are only based on the positive/negative aspects of factors. Therefore, the use of quantitative assessment with tools is recommended in order to improve HIA effectiveness, as well as to allow estimates on the magnitude of impacts (Woodcock et al., 2009).

\section{Methodology}

The methodology in this paper consists of four steps. The first is brainstorming the costs and the expected benefits associated with unmanned parcel lockers. Next, we monetized the practical costs of installing unmanned parcel lockers. Then, the expected benefits were estimated from secondary sources, and with proper analyses or recommended tools. Finally, this paper calculates several performance indexes to deploy conclusions about the feasibility of the project.

Because the maintenance cost for the lockers is a negligible amount, only the locker installation was considered. Customers only walk inside a small residential area, and therefore, this research excludes parking cost savings and crash risk decreases (safety). Our CBA model estimates the expected impacts from four factors: travel time savings, vehicle operation cost savings, environment cost savings, and public health benefits.

\subsection{Expected benefit estimation}

Travel time savings. First, the average travel times of the trucks before and after project implementation were estimated. Then, the appropriate travel time unit cost value was applied to estimate the total value of travel time savings. Mentioned studies in the literature review provided several suggested values, which came from several geographic regions for various research purposes. However, if local data are available and reliable, local specific VTTS is recommended for estimations because they reflect exact regional conditions. In Korea, local research by Choi and Park (2013) provided VTTS that covered freight transport modes in Korea based on the wage rates of Korean drivers.

Vehicle operating cost savings. As mentioned above, vehicle costs are direct financial costs to operate vehicles. Those costs are affected significantly by various sources, like total distance traveled, conditions and locations of operating, and other environmental factors (pavement roughness, slopes, etc.). Therefore, it is difficult to set up a model that estimates them with high accuracy. Several suggested values from surveys and research exist in the literature. Barnes and Langworthy (2004) focused on frequent stop-start driving conditions for light-duty trucks, which is similar to in-city delivery truck operation. The operational costs consist of practical costs: maintenance and repair costs, tire cost, and depreciation.

Fuel-environmental cost savings. The total emissions of each pollutant are estimated by applying complicated factors and collecting data like traveled distance, input stock, and activity data (vehicle mileage, circulation, and population) from users and several specific vehicle parameters. Simulation is an adequate method to estimate fuel and emissions savings, in this case. In general, microscopic models are preferred, because the results are more reliable and realistic; however, they also require high-quality and detailed data. COPERT is frequently used software for various targets, and provides default inputs that reduce the reliance on the availability of specific local input data. Additionally, a Geographic Information System technique was used to generate distances traveled by truck before and after project implementation.

The in-use fuel consumption function of COPERT is expressed in the following equation:

$$
F C=0.000278 F e_{i} b_{e}\left[m\left(9.81 r_{0}+1.05 b e a\right)+\left(\frac{v}{3.6}\right) m \cdot g \cdot r_{1}+0.6\left(\frac{v}{3.6}\right)^{2} c_{d} A\right]
$$

where $F e_{i}$ is engine efficiency improvements compared to Euro 5 engines, $b_{e}$ is brake-specific fuel consumption (g/kWh), 
bea is acceleration $\left(\mathrm{m} / \mathrm{s}^{2}\right), m$ is reference mass (empty weight $+75 \mathrm{~kg}$ for driver and $20 \mathrm{~kg}$ for fuel), $r_{0}$ and $r_{1}$ is rolling resistance coefficients when accelerating, $c_{d} A$ is aerodynamic resistance $\left(\mathrm{m}^{2}\right)$, and $v$ is average speed of the vehicle $(\mathrm{km} / \mathrm{h})$. Emissions include exhaust and non-exhaust pollutants. Exhaust emission ( $\mathrm{E}_{\mathrm{exh}}$ ) refers to gases and particulate matter (PM) discharged by the engine. It is calculated with the equations below.

Emissions from engine $k$ at normal operation:

$$
\begin{aligned}
E_{h o t, k} & =D \cdot e f_{h o t, k} \\
e f_{h o t, k} & =\frac{a \cdot v^{2}+b \cdot v+c+d / v}{e \cdot v^{2}+f \cdot v+g}(1-R F)
\end{aligned}
$$

where $D$ is traveled distance, $e f_{h o t, k}$ is an emission factor of engine $k$ at normal operation, $v$ is average speed of the vehicle, coefficients $a$ to $g$ are empirically derived for each engine with environmental conditions, and $R F$ is specific coefficients of reduction factors.

Emissions from engine $k$ when starting are:

$$
\begin{aligned}
& E_{\text {cold }, k}=\beta \cdot L \cdot e f_{\text {hot }, k}\left(\frac{e f_{\text {cold }}}{e f_{\text {hot }}}-1\right) \\
& \frac{e f_{\text {cold }}}{e f_{\text {hot }}}=l-m \cdot \text { temp }
\end{aligned}
$$

where $L$ is trip length, $\beta$ is the fraction of mileage driven with a cold engine or the catalyst operated below the light-off temperature, $e f_{\text {cold }} / e f_{\text {hot }}$ is the cold/hot emission quotient for vehicles of technology $k$, temp is the ambient temperature, $l$ $=1.47, m=0.009$ for gasoline, and $l=1.34, m=0.008$ for diesel.

Thus, exhaust emissions from engine $k$ are:

$$
E_{\text {exh }}=E_{\text {hot }, k}+E_{\text {cold }, k}
$$

Emissions from fuel evaporation $\left(E_{\text {evap }}\right)$ are:

$$
E_{\text {evap }}=E_{\text {diurnal }}+E_{\text {soak }}+E_{\text {running }}
$$

where $E_{\text {diurnal }}$ is fuel loss due to temperature changes during the day, $E_{\text {soak }}$ is fuel loss when hot fuel is kept in the reservoir after operation, and $E_{\text {runing }}$ is fuel loss when fuel runs back into the reservoir during operation.

The amount of PM emitted from tire and brake attrition is:

$$
E_{\text {att }}=D \cdot e f_{p m}
$$

where $e f_{P M}$ is the PM emission factor for tire and brake attrition.

From (1), (2), (3), we have the total emissions ( $\left.\mathrm{E}_{\text {reduced }}\right)$ from a reduced distance, calculated as:

$$
E_{\text {reduced }}=\sum E_{\text {exh }}+E_{\text {evap }}+E_{\text {att }}
$$

After generating the amount of reduced emissions, the expected environmental cost savings $\left(\mathrm{S}_{\text {env }}\right)$ are calculated with the formula below:

$$
S_{\text {env }}=\sum_{1}^{m}\left(E_{\text {reduced }, m} \cdot M C_{m}\right)
$$

where $m$ is the kind of $\mathrm{m}$ is the kind of pollutants, $E_{m}$ is the amount of emitted pollutant $m$, and $M C_{m}$ is the environmental costs of pollutant $m$.

The environmental cost of carbon dioxide $\left(\mathrm{CO}_{2}\right)$ was obtained from the Korea Carbon Price. For other pollutants like SOx, NOx, and PM, the environmental costs were obtained from Air Quality Damage Costs per ton in 2015 from the U.K. Department for Environment, Food and Rural Affairs (2015), and a social discount rate (SDR) was applied for the period from 2015 to 2017.

Public health benefit: Active transport can gain various significant health benefits for people who enjoy more physical activities. The Health Economic Assessment Tool (HEAT) proposed by the WHO estimates public health benefits from 
active transportation activities. To capture health benefits from the physical activity of pedestrians, the mortality risk of premature death from any cause of the considered pedestrian group (the exposed group, MRe) is estimated based on the risk of premature death from any cause of the unexposed group $(\mathrm{MRu})$ and the relative risk (RRwalking), as shown below:

$$
M R_{e}=R R_{\text {walking }} M R_{u}
$$

Because pedestrians breathe more air pollutants than people who stay at home or who ride in a car, in the tool, $R R_{\text {walking }}$ was adjusted, compared to ones in other studies referred to. Then, the difference in the number of deaths between the two groups is considered to be the number of deaths attributed to the impact of active physical activity, as follows.

Number of deaths in the unexposed group $D_{u}=M R_{u} P O P_{u}$

Number of deaths in the exposed group $D_{e}=M R_{e} P O P_{e}$

Number of deaths attributed $D_{a t t}=D_{e}-D_{u}$

where $P O P$ is the population of each group, $e$ is the exposed group, and $u$ is the unexposed group.

The value for premature deaths is converted into a monetary term based on the concept of value of a statistical life (VSL) and the value of a life-year (VLY). VSL is the individual's willingness to pay to avoid premature death and is calculated based on statistical life expectancy. VLY is the constant value of VSL in one year for the years that a person is expected to live. VSL for a Korean is calculated as follows:

$$
V S L_{\text {KOR.2016KRW }}=V S L_{\text {OECD } .2005(\$)} \frac{Y_{K O R .2005}^{0.8}}{Y_{\text {OECD.2005 }}} P P P_{2005}\left(1+\% \Delta C P I_{K O R .2005-2017}\right)\left(1+\% \Delta Y_{K O R .2005-2017}\right)^{0.8}
$$

where $V S L_{O E C D .2005(\$)}$ is the base value from the Organization for Economic Co-operation and Development (OECD) for the U.S.: $\$ 3.013$ million from one OECD study, $Y_{K O R .2005}$ is the real gross domestic product (GDP) per capita for Korea in 2005, $Y_{O E C D .2005}$ is the average real GDP per capital at purchasing power parity in 2005 from the OECD, which equals US\$30,801, $P P P_{2005}$ is the exchange rate adjusted for purchasing-power parity in 2005 (local currency per US\$), 0.8 is income elasticity of VSL according to OECD studies, $1+\% \triangle C P I_{K O R .2005-2017}$ is an inflation adjustment from the consumer price index in Korea between 2005 and 2017, and 1+\% $Y_{K O R .2005-2017}$ is an income adjustment from growth in real GDP per capita for Korea between 2005 and 2017. Then, VLY is a function based on VSL using the equation below:

$$
V L Y=\frac{\overline{V S L}}{A(T-a, r)}
$$

where $A(T-a, r)$ is the annuity factor, $r$ is the SDR, and $T-a$ is the person's remaining years of life.

Finally, the public health benefit $\left(\mathrm{B}_{\text {health }}\right)$ is estimated as follows:

$$
B_{\text {helath }}=D_{\text {att }} V L Y
$$

\subsection{Period of the project}

The selection of a time horizon significantly affects evaluating the results of the project. Therefore, it should be obtained from a standard benchmark, which varies in different sectors and is based on globally accepted practice. The value of 10 years, which is recommended in the Guide to Cost-Benefit Analysis of Investment Projects - an economic appraisal tool for Cohesion Policy 2014-2020 of the European Commission (EC) - was selected to evaluate this project. The implementation period is also recommended, but in this case, due to simple installations of parcel locker stations, the implementation period is considered 0 .

\subsection{Social discount rate in analysis}

The monetary value of benefits accruing or costs borne over a long time period until some point in the future are often considered lower than those for today, even with no inflation, and thus, researchers and economists generally apply an SDR for the future to set both present and future values to the same metric (Simonelli, 2013). Therefore, selection of the SDR value plays a crucial role in quantitative values, and significantly affects performance indexes and the final decisions of the decision maker. However, while the financial research cycle agrees on a common approach to figure out the financial discount rate, there has been continuing crucial contention about the choice of an appropriate SDR, which should be applied to projects, among the researchers who have carried out CBA (U.S. Office of Management and Budget, 1992). The U.S. and the EU, which both enforce guidelines for project and policy assessments, also estimate discount rates in 
different ways. U.S. institutional actors suggest rates of $3 \%$ for government investment (U.S. Office of Management and Budget 1992 and 2003, U.S. Environmental Protection Agency, 2010). In all cases, benefits and costs should be applied with the same SDR, and risk and uncertainty should be ignored from the SDR. On the other hand, the above-mentioned EC guideline recommends only one common SDR of 4\%. The SDR is applied to find the current value of variables used in the analysis by following the equation below:

$$
A_{n}=A_{0}(1+r \%)
$$

where $A_{n}$ is the amount at the calculating point, $A_{0}$ is the principle amount as of the base year, $r$ is the SDR per annum, and $n$ is the number of years.

\subsection{Selection of decision criteria}

After estimating the expected benefits, this paper assesses the performance of the project to see whether it sounds reliable, sustainable, and profitable or not. This study follows the EU guideline (50) to evaluate the project. However, because this project is funded by the government, it is unnecessary to carry out a financial analysis to see whether the project needs government financial assistance or not. Instead, economic performance is the focus in this study. Economic performance is measured by the three following main indexes.

Economic net present value (ENPV): the deduction from discounted total social benefits to costs, calculated based on the following equation:

$$
E N P V=\sum_{t=0}^{n} a_{t} N_{t}=\frac{N_{0}}{(1+i)^{0}}+\frac{N_{1}}{(1+i)^{1}}+\cdots+\frac{N_{n}}{(1+i)^{n}}
$$

where $N_{t}$ is the net economic benefit at time $t, a_{t}$ is the economic discount factor chosen for discounting at time $t, i$ is the $\mathrm{SDR}$, and $\mathrm{n}$ is the total years for the project.

Economic rate of return (ERR): the rate that makes ENPV equal to zero, calculated as:

$$
0=\sum \frac{N_{t}}{(1+E R R)^{t}}
$$

$B / C$ ratio: the ratio between discounted total benefits and costs. The higher the ratio, the more benefits received per unit of money paid. The project or policy that has an ERR lower than the SDR or a negative ENPV, should be rejected.

\subsection{Sensitivity analysis}

Last but not least, guidelines from both the U.S. and the EC (U.S. Environmental Protection Agency, 2010; European Commission, 2014) indicate that a sensitivity analysis is also necessary to tackle conflicting SDR values. The Korean government funds the project, and therefore, we will follow the U.S. guideline to examine costs and benefits, and the EC's value is selected to conduct a sensitivity analysis to compare, and to figure out the contribution of the SDR to the project's performance - if there is a $1 \%$ variation in the SDR, how well the performance index will be changed. In addition, another sensitivity analysis was conducted to examine performance elasticity in the case of changes in the main costs and benefits. In both analyses, if the absolute change is greater than $1 \%$, the impact on economic performance is considered critical. Another important component of the sensitivity analysis with cost and benefit variables is the switching value with this value, a critical variable can make the outcome of the project drop below the minimum threshold of acceptability. Switching value is the foundation of risk-prevention decisions in evaluating the project.

\section{Empirical analysis}

\subsection{Study area}

The study area is located in Guweol-dong, Incheon Metropolitan City, Korea. Guweol-dong has a population of 25,400 in a total area of $1.76 \mathrm{~km} 2$, including abundant, small, densely residential areas. The target region is concentrated, with small detached houses, and thus, critically needs the unmanned parcel lockers. Lee et al. (2017) pointed out three optimized locations for installing the lockers in the same case study. Assumed is that, without any lockers, a delivery truck has to make 16 stops like the ones shown in Figure 1 below. Without lockers, at each stop, it is assumed that the driver needs about 10 minutes to park the truck, unload and bring packages to the door of each house, call the customer 
or take a picture, and go back to the truck. However, if lockers are installed, it is assumed that the driver makes only three stops and spends 15 minutes at each location to put the packages into the lockers, and saves the time to walk to every house. Delivery service arrives once per day, six days per week (including holidays, but excluding Sundays); therefore, in one year (52 weeks), the number of working days is 312 . By referring to secondary sources and calculations, after applying the SDR, we estimate values for variables in 2017, which are shown in Table 1.

Table 1. T\&C bilate

\begin{tabular}{|c|c|c|c|}
\hline \multicolumn{2}{|c|}{ Variables } & Value in 2017 & Unit \\
\hline \multicolumn{2}{|c|}{ VTTS } & 22,510 & KRW/h \\
\hline \multicolumn{2}{|c|}{ VOC savings } & 1,449 & $\mathrm{KRW} / \mathrm{km}$ \\
\hline \multicolumn{2}{|c|}{ Fuel price (diesel) } & 1,251 & KRW/L \\
\hline \multirow{4}{*}{$\begin{array}{c}\text { Environmental } \\
\text { cost savings }\end{array}$} & $\mathrm{CO}_{2}$ & 22,000 & KRW/ton \\
\hline & PM & $91,978,618$ & $\mathrm{KRW} /$ ton \\
\hline & $\mathrm{SO}_{\mathrm{x}}$ & $3,095,229$ & KRW/ton \\
\hline & $\mathrm{NO}_{\mathrm{x}}$ & $39,959,468$ & KRW/ton \\
\hline \multicolumn{2}{|c|}{ Korean VSL } & $4,941,382,614$ & KRW/person \\
\hline \multicolumn{2}{|c|}{ Korean VLY } & $68,407,768$ & $\mathrm{KRW} /$ person/remaining years \\
\hline \multicolumn{2}{|c|}{ Initial investment } & $39,000,000$ & KRW \\
\hline
\end{tabular}

\subsection{Results}

The economic performance of this project is presented in Table 2 with an SDR of 3\% and a 10-year lifetime for the project. The ERR of this project is 79\%, greater than the SDR (3\%). The ENPV is KRW123,615,802, greater than 0. It means this project should be accepted. The benefit-cost ratio is 4.89 , which means that per unit of money invested, we can get back nearly five units of benefit. Therefore, it is undeniable that this project is critically beneficial to the community.

Table 2. Economic performance with SDR $=0.03$ (Unit: KRW1000)

\begin{tabular}{ccccccc}
\hline & \multicolumn{3}{c}{ Year } & \multicolumn{3}{c}{} \\
\cline { 2 - 6 } & 1 & 2 & 3 & $4-8$ & 9 & 10 \\
\hline Time savings & 13,506 & 13,911 & 14,329 & $\ldots$ & 17,109 & 17,622 \\
Vehicle cost savings & 1,000 & 1,030 & 1,060 & $\ldots$ & 1,266 & 1,304 \\
Emission savings & 75 & 77 & 79 & $\ldots$ & 94 & 97 \\
Public health benefits & 2,052 & 2,114 & 2,177 & $\ldots$ & 2,600 & 2,678 \\
Total benefits & 16,632 & 17,131 & 17,645 & $\ldots$ & 21,069 & 21,702 \\
Initial investment & 39,000 & 0 & 0 & 0 & 0 & 0 \\
Total costs & 39,000 & 0 & 0 & 0 & 0 & 0 \\
Net economic benefit & $-22,368$ & 17,131 & 17,645 & $\ldots$ & 21,069 & 21,702 \\
ENPV & & & & 123,616 & & \\
ERR & & & & 0.79 & & \\
B/C ratio & & & & & \\
\hline
\end{tabular}

The proportion of the contribution-of-benefit categories to the total benefit shows that the most decisive contribution came from travel time savings, at $81 \%$, followed by public health benefits (12\%), vehicle cost savings (6\%), and emission savings (less than 1\%).

\section{Sensitivity analysis}

\subsection{Variation in $S D R$}

A sensitivity analysis with a $1 \%$ variation in SDR was conducted. The applied SDR is $4 \%$, as in the recommendation of the EC guideline. The new outputs are shown in Table 3. The new ERR is 0.86, and the new ENPV is positive, at KRW128,630,000. The project with the new SDR should be accepted, and all new indexes show greater values than the original ones. With the $1 \%$ increase in SDR, new indexes for ENPV, ERR, and B/C ratio are amplified critically at $4.06 \%$, $9.13 \%$, and $8.79 \%$, respectively. Therefore, the SDR has contributed crucially to the project, and the selection of the SDR may be weighty in determining the performance of the project. 


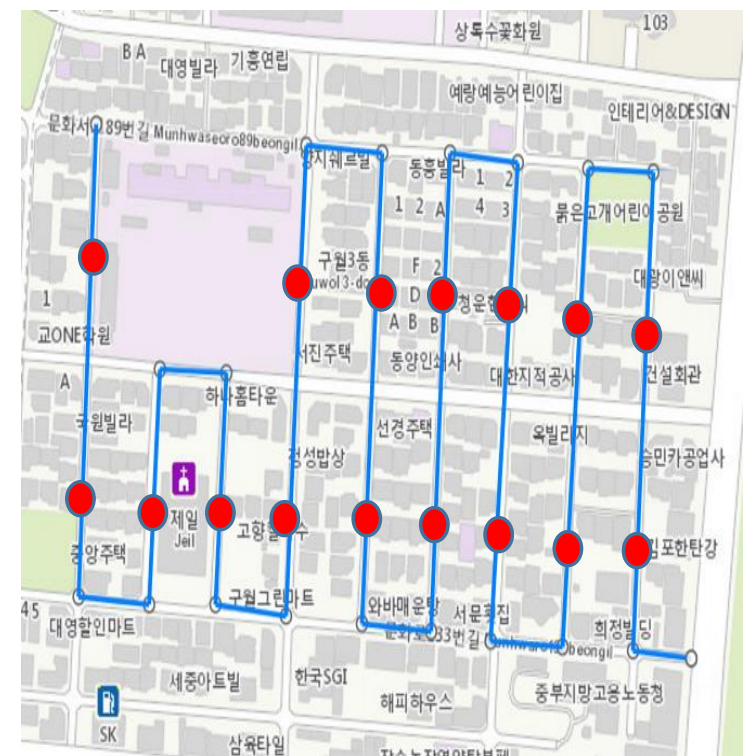

(a)

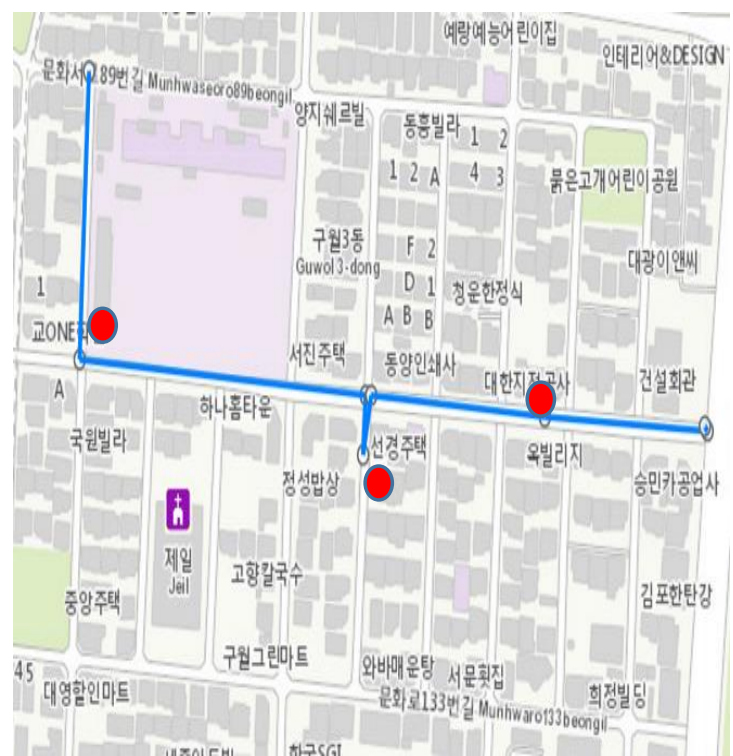

(b)

Figure 1. Assumption of truck stops: (a) without lockers, and (b) with installed lockers. Notes: Red circles represent truck stops.

Table 3. Economic performance with SDR = 0.04 (Unit: KRW1000)

\begin{tabular}{ccccccc}
\hline & \multicolumn{3}{c}{ Year } & \multicolumn{3}{c}{} \\
\cline { 2 - 6 } & 1 & 2 & 3 & $4-8$ & 9 & 10 \\
\hline Time savings & 14,038 & 14,600 & 15,184 & $\ldots$ & 19,212 & 19,981 \\
Vehicle cost savings & 1,111 & 1,156 & 1,202 & $\ldots$ & 1,521 & 1,582 \\
Emission savings & 76 & 79 & 82 & $\ldots$ & 104 & 108 \\
Public health benefits & 2,052 & 2,134 & 2,220 & $\ldots$ & 2,809 & 2,921 \\
Total benefits & 17,278 & 17,969 & 18,687 & $\ldots$ & 23,645 & 24,591 \\
Initial investment & 39,000 & 0 & 0 & 0 & 0 & 0 \\
Total costs & 39,000 & 0 & 0 & 0 & 0 & 0 \\
Net economic benefit & $-21,722$ & 17,969 & 18,687 & $\ldots$ & 23,645 & 24,591 \\
ENPV & & & & 128,630 & & \\
ERR & & & & 0.86 & & \\
B/C ratio & & & & & \\
\hline
\end{tabular}

\subsection{Variation in variables}

Another sensitivity analysis was conducted with a change in variables. Only VTTS is considered a critical variable for the sensitivity of economic performance. The $1 \%$ variation in the VTTS is responded to by a $1.06 \%$ absolute change in the ENPV value. Therefore, only the switching value for the value of traveled time is calculated, and in this case, it is $-95 \%$. That means that if the value of traveled time falls below 95\%, the ENPV of a 10-year project will be negative, and the project should be rejected. Results are shown in Table 4.

Table 4. Result of sensitivity analysis with variations in variables (\%)

\begin{tabular}{|c|c|c|c|}
\hline \multirow{2}{*}{ Variables } & \multicolumn{2}{|c|}{ ENPV elasticity } & \multirow{2}{*}{$\begin{array}{c}\text { Switching value } \\
(\mathrm{ENPV}=0)\end{array}$} \\
\hline & $+1 \%$ of variable & $-1 \%$ of variable & \\
\hline Value of traveled time & +1.06 & -1.06 & -95 \\
\hline Vehicle costs & +0.06 & -0.06 & - \\
\hline Fuel price & +0.018 & -0.018 & - \\
\hline Pollutants' damage costs & +0.0009 & -0.0009 & - \\
\hline $\mathrm{PM}$ & +0.0005 & -0.0005 & - \\
\hline $\mathrm{SO}_{\mathrm{x}}$ & $\sim 0$ & $\sim 0$ & - \\
\hline $\mathrm{NO}_{\mathrm{x}}$ & +0.004 & -0.004 & - \\
\hline Korean VLY & +0.16 & -0.16 & - \\
\hline Initial investment & -0.3 & +0.3 & - \\
\hline
\end{tabular}




\section{Conclusion and further research}

This study establishes a framework for social benefits and costs in setting up unmanned parcel lockers in residential areas of Korean cities. A case study in Incheon Metropolitan City was conducted to verify the cogency of the framework. Regarding the above economic performance and sensitivity analyses, they no doubt conclude that this project is beneficial to the community. The economic net present value is KRW123,616,000 after 10 years, and the benefit-cost ratio is high, at 4.89. Time savings presented an absolute dominance in terms of the total value of benefits. Public health benefits are also denoted as considerable, and were ranked second. Economic benefits from vehicle cost savings alone are not attractive enough to make the project profitable. In addition, compared to the contribution of time savings or other benefit variables, although emissions savings is not significant, this is one of the principal goals of the community, and it could not be denied due to its important role in protecting the current living environment. The project of unmanned parcel lockers is planned to expand nationwide, and hence, an economy of scale can be achieved. Not only corresponding with geographic expansion, the benefits from non-motorized transport modes can also increase significantly due to links with other economic opportunities located in walking environments, like retail, dining, and entertainment fields. In addition, the preliminary costs of installing lockers also can decrease significantly due to purchasing lockers on a large scale.

In addition, delivery companies can obtain benefits by reducing travel time (e.g. wages paid to drivers) and vehicle costs, and therefore, they should pay more attention to this issue and share the cost burden in order to expand the number of unmanned parcel lockers. Therefore, the government should also prepare public-private partnership (PPP) operational plans to appeal for more delivery company involvement, and then, to reduce the contribution of public assistance. Another thing the government should support in the policy is setting parcel lockers in semi-public locations to optimize land costs (this research considered chosen locations as public locations with land cost at 0 in the analysis).

Finally, although this study was conducted using various models and estimations with the support of software, it also consists of several degrees of variability and uncertainty due to limited cognition and data on both benefit and cost variables. Therefore, a sensitivity analysis was conducted to figure out critical factors affecting performance of the project through variations of risk-preventing actions. A social discount rate and the value of travel time were found to be critical factors in this case. The switching value of VTTS was -95\% (approximately KRW1126/hour). In fact, it is impossible in reality because the referred Korean VTTS was calculated based on Korean drivers' wages (the current minimum hourly value is KRW7530/hour, which is much bigger, compared to the calculated switching value). However, the contribution of the VTTS to the final result, as discussed above, is essential and undeniable. In addition, both of them are secondary data, which were obtained from preceding research studies. Thus, it prompts a demand to conduct more reliable research about the social discount rate and the value of time for Korean cases in the future.

\section{References}

Allen, B., Hamilton Inc., 1999. California Life Cycle Benefit/Cost Analysis Model. California Department of Transportation, Sacramento, CA, US.

Asano, M., Tanabe, S., Hara, F., Yokoyama, S., 2002. Economic evaluation of banning studded tires because of environmental impact. Transportation Research Record 1794, 84-93.

Asia Today, 2014. Mandatory installation of more than 500 people in apartment buildings and unmanned delivery service.

Barnes, G., Langworthy, P., 2004. Per mile costs of operating automobiles and trucks. Transportation Research Record 1864, 71-77.

Barth, M., Boriboonsomsin, K, 2008. Real-world CO2 impacts of traffic congestion. Transportation Research Record 2058, 163-171.

Barth, M., Younglove, T., Scora, G., 2005. Development of A Heavy-duty Diesel Modal Emissions and Fuel Consumption Model. Technical report, UC Berkeley: California Partners for Advanced Transit and Highways (PATH), California.

Berger, L., Associates, 1998. Guidance for Estimating the Indirect Effects of Proposed Transportation Project. Transportation Research Board, Washington D.C., US.

Berwick, M., Dooley, F., 1997. Truck Costs for Owner/Operators. Upper Great Plains Transportation Institute, North Dakota State University, Fargo.

Brand, D., Parody, T.E., Orban, J.E., Brown, V.J., 2002. Benefit-Cost analysis of the commercial vehicle information systems and networks program. Transportation Research Record 1800, 35-43.

Bristow, A.L., Nellthorp, J., 2000. Transport project appraisal in the European Union. Transport Policy 7, 51-60.

Choi, C., Park, D., 2013. A Study of appropriate amounts and applicable ranges of the travel time values of goods in Korea. Journal of the Korean Society for Railway 16, 418-429.

Coombs, H., Jenkins, E., Hobbs, D., 2005. Management Accounting: Principles and Applications. SAGE Publications, London.

Demir, E., Bektaş, T., Laporte, G., 2014. A review of recent research on green road freight transportation. European Journal of Operational Research 237, 775-793.

DJM Consulting, ECO Northwest, 2002. Benefit-Cost Analysis of the Proposed Monorail Green Line. Prepared for the Elevated Transportation Company, Seattle, WA.

European Commission, 2014. Guide to Cost-Benefit Analysis of Investment Project - Economic appraisal tool for Cohesion Policy 2014-2020. Office of Regional and Urban policy, European Commission.

Ford, T.W.IV., Dan, M., 2015. An Analysis of the Operational Costs of Trucking: 2015 Update. ATRI, Arlington, Virginia.

Glass, G.V., Smith, M.L., McGaw, B., 1981. Meta-analysis in Social Research. Sage Publications, London.

Hanley, N., Spash, C.L., 1993. Cost-benefit Analysis and the Environment. Edward Elgar Publishing Ltd., Cheltenham. 
Hanson, M.E., 1992. Results of Literature Survey and Summary of Findings: The Nature and Magnitude of Social Costs of Urban Roadway Use. Contract DTFH61-91-P-01345, Federal Highway Administration, US Department of Transportation.

HEI, 2010. Traffic-Related Air Pollution: A Critical Review of the Literature on Emissions, Exposure, and Health Effects. Health Effects Institute, Boston, MA.

Hensher, D.A., 2001. Measurement of the valuation of travel time savings. Journal of Transport Economics and Policy 35, 71-98.

Jack Faucett Associates, 1991. The Effect of Size and Weight Limits on Truck Costs. Department of Transportation, US.

Kågeson, P., 1993. Getting the Prices Right: A European Scheme for Making Transport its True Costs. European Federation for Transport and Environment.

Keeler, T.E., Small, K., 1975. The Full Costs of Urban Tranport Part III: Automobile Costs and Final Intermodal Cost Comparisons. Institute of Urban and Regional Development, University of California.

Korean Ministry of Gender Equality and Family, 2016. National Sexual Violence Survey 2016.

Kouridis, C., Gkatzoflias, D., Kioutsioukis, I., Ntziachristos, L., Pastorello, C., Dilara, P., 2010. Uncertainty Estimates and Guidance for Road Transport Emission Calculations. Publications Office of the European Union, Ispra.

Laporte, A., Dubreuil, M., 2014. Évaluation des Impacts Sur La Santé Des Projets Transport À Plaine Commune. Paris: Agence régionale de santé (ARS) Île-de-France, Observatoire régional de la santé (ORS) Île-de-France, synthèse rapport final mai.

Lee, H., Chen, M., Choo, S., 2017. Developing an optimal location selection methodology of unmanned parcel service box. The Journal of the Korea Institute of Intelligent Transportation System 16, 13-24.

Lehtonen, M., Kulmala, R., 2002. Benefits of pilot implementation of public transport signal priorities and real-time passenger information. Transportation Research Record 1799, 18-25.

Li, J., Gillen, D., Dahlgren, J., 1999. Benefit-cost evaluation of the electronic toll collection system: A comprehensive framework and application. Transportation Research Record 1659, 31-38.

Litman, T., 2009a. Transportation Cost and Benefit Analysis. Victoria Transport Policy Institute, Victoria, Canada.

Litman, T., 2009b. Climate Change Emission Valuation for Transportation Economic Analysis. Victoria Transport Policy Institute, Victoria, Canada.

Litman, T., 2013. Transportation Cost and Benefit Analysis: Techniques, Estimates and Implications. Victoria Transport Policy Institute, Victoria, Canada.

MacKenzie, J.J., Dower, R.C., Chen, D.D., 1992. The Going Rate: What It Really Costs to Drive. World Resources Institute, Washington, DC, US.

Mackie, P.J., Jara-Diaz, S., Fowkes, A.S., 2001. The value of travel time savings in evaluation. Transportation Research Part E: Logistics and Transportation Review 37, 91-106.

McKinsey and Company, 1986. Afrekenen Met Files: Samenvatting, Conclusies en Aanbevelingen. Amsterdam.

Mindell, J.S., Boltong, A., Forde, I., 2008. A review of health impact assessment frameworks. Public Health 122, 1177-1787.

NEA, 1991. Filekosten op het Nederlandsehoofdwegennet in 1990. NEA, Rijswijk, Netherlands.

Ross, C.L., Orenstein, M., Botchwey, N., 2014. Health Impact Assessment in the United States, Springer, New York, US.

Scora, G., Barth, M., 2006. Comprehensive modal emission model (CMEM), version 3.01: User's guide, Technical report, University of California, US.

Simonelli, F., 2013. The role of the discount rate in cost-benefit analysis between theory and practice: A comparative survey. European Journal of Risk Regulation 4, 59-71.

Sunstein, C. R., 2005. Cost-benefit analysis and the environment. Ethics, 115(2), 351-385.

The California Department of Transportation (Caltrans), 1974. Highway Economic Evaluation Model. Caltrans, CA, US.

Transport Canada, 1994. Guide to Benefit-Cost Analysis in Transport Canada. Transport Canada, Ottawa, Canada.

Trimac Logistics Ltd., 2001. Operating Costs of Trucks in Canada. Transport Canada, Economic Analysis Directorate, Canada.

Tsamboulas, D., Pearman, A., Larkinson, J., Leleur, S., 1999. Comparing the Economic Performance and Environmental Impact of Trans-European Road Networks: The EUNET Project and Assessment Tool. DG VII, Bruxelles, Belgium.

U.K. Department for Environment, Food and Rural Affairs, 2015. Air Quality: Economic Analysis.

United Nations Environment Programme (UNEP), 2007. Global Environmental Outlook 4.

U.S. Department of Transportation, 2007. Benefit-Cost Analysis in Public Sector Infrastructure Investment Decisions. Paper prepared for the National Surface Transportation Policy and Revenue Study Commission.

U.S. Environmental Protection Agency, 2010. Guidelines for Preparing Economic Analyses. National Center for Environmental Economics, Office of Policy, U.S. Environmental Protection Agency.

U.S. International Trade Administration, 2017. Korea Country Commercial Guide.

U.S. National Research Council, 2011. Improving Health in the United States: The Role of Health Impact Assessment. The National Academies Press, Washington, DC.

U.S. Office of Management and Budget, 1992. Circular A-94 of the Office of Management and Budget, Guidelines and Discount Rates for Benefit-Cost Analysis of Federal Programs.

U.S. Office of Management and Budget, 2003. Circular A-4 of the Office of Management and Budget, Regulatory Analysis.

Waheed, F., Ferguson, G.M., Ollson, C.A., MacLellan, J.I., McCallum, L.C., Cole, D.C., 2018. Health impact assessment of transportation projects, plans and policies: A scoping review. Environmental Impact Assessment Review 71, 17-25.

Widlert, S., Bradley, M., 1992. Preferences for Freight Services in Sweden. Sixth World Conference in Transport Research, Lyon, France.

Woodcock, J., Edwards, P., Tonne, C., Armstrong, B.G., Ashiru, O., 2009. Public health benefits of strategies to reduce greenhousegas emissions: urban land transport. The Lancet 374, 1930-1943.

World Health Organization, 1948. Preamble to the Constitution of the World Health Organization, proceedings of the International Health Conference, New York, US.

World Health Organization, 1999. European Centre for Health Policy, Geneva, Switzerland.

Yoon, J., 2012. Improvement Tasks through Analysis of the Actual State of Urban Housing. Korea National Assembly Research Service (NARS), Seoul, Korea. 
Analyzing the costs and benefits of installing unmanned parcel lockers: Focusing on residential complexes in Korea

Yoon, J., 2017. Top 5 E-commerce sites in South Korea.

Zaniewski, J.P., Butler, Jr. B.C., Cunningham, G., Elkins, G.E., Paggi, M., Machemehl, R., 1982. Vehicle Operating Costs. Fuel Consumption, and Pavement Type and Condition Factors, prepared for U.S. Department of Transportation. Federal Highway Administration, Washington, DC, US. 